\title{
COMPARATIVE STUDY OF EPIDURAL ROPIVACAINE WITH DEXMEDETOMIDINE, ROPIVACAINE WITH CLONIDINE AND ROPIVACAINE ALONE FOR PERIOPERATIVE ANALGESIA IN ABDOMINAL HYSTERECTOMY
}

\author{
Satheedevi P1, Rasikapriya $M^{2}$, Chithra ${ }^{3}$ \\ ${ }^{1}$ Additional Professor, Department of Anaesthesiology, GMCH, Thrissur. \\ ${ }^{2}$ Senior Resident, Department of Anaesthesiology, GMCH, Thrissur. \\ ${ }^{3}$ Assistant Professor, Department of Anaesthesiology, GMCH, Trivandrum.
}

\section{ABSTRACT}

Regional anesthesia is widely used for abdominal hysterectomies. It is divided into spinal and epidural anaesthesia. Epidural anesthesia has got the advantage of extending the period of anesthesia to post-operative analgesia. We can use various pharmacological agents as adjuvants, which prolong the duration of action of local anesthetics. They include opiods, alpha 2 agonists like clonidine and dexmedetomidine. In this we studied the efficacy of local anesthetic agent - ropivacaine alone, ropivacaine with clonidine and ropivacaine with dexmedetomidine for epidural block. Present study showed that Epidural Dexmedetomidine and clonidine have synergistic action in combination with epidural ropivacaine resulting in smooth and prolonged postoperative analgesia and sedation. Group RD (Ropivacaine and Dexmedetomidine) had significant difference in comparison of postoperative block characteristics, such as time of two segment regression, time to Bromage scale 1, time of regression to S1 dermatome and time of first epidural top up than group RC and R. (Ropivacaine with clonidine and Ropivacaine alone). Thus epidural dexmedetomidine is a better neuraxial adjuvant in combination with epidural ropivacaine in producing prolonged analgesia and better sedation for abdominal hysterectomy.

\section{KEYWORDS}

General Anesthesia, Epidural Block, Abdominal Hysterectomy, Ropivacaine, Dexmedetomidine, Clonidine Blood Pressure, Preoperative Analgesia.

HOW TO CITE THIS ARTICLE: Satheedevi P, Rasikapriya M, Chithra. "Comparative Study of Epidural Ropivacaine with Dexmedetomidine, Ropivacaine with Clonidine and Ropivacaine Alone for Perioperative Analgesia in Abdominal Hysterectomy". Journal of Evolution of Medical and Dental Sciences 2015; Vol. 4, Issue 95, November 26; Page: 16072-16079,

DOI: $10.14260 /$ jemds/2015/2348.

\section{INTRODUCTION}

General Anesthesia or Regional anesthesia (Spinal/Epidural) is the technique used for Abdominal Hysterectomy surgeries. Regional anesthesia is preferred for lower abdominal surgeries. Epidural anesthesia is a neuraxial technique which is used in this study is one of the safest and easier techniques for lower abdominal surgeries. The principal advantages of epidural anesthesia are lower risk for post dural puncture headache, less systemic hypotension, the ability to produce a segmental sensory block, skeletal muscle relaxation and contraction of the gastrointestinal tract are also produced by a regional anesthetic. Disadvantages of this anesthetic technique include the occasional failure and hypotension.

The commonly used local anesthetics in epidural anesthesia are lignocaine and bupivacaine. Ropivacaine is the local anesthetic used in this study has a greater propensity to produce vasoconstriction in addition to a more favorable interaction with cardiac sodium ion channels. This may contribute to its reduced cardiotoxicity. ${ }^{1}$ than bupivacaine. Sedation, anxiolysis, patient satisfaction is a valuable tool required during regional anesthesia to make it more convenient for the patient, the anesthetist, and the surgeon.

Financial or Other, Competing Interest: None.

Submission 06-11-2015, Peer Review 07-11-2015,

Acceptance 18-11-2015, Published 25-11-2015.

Corresponding Author:

Dr. Satheedevi $P$,

Amala Hospital Quarters A1,

Amala Nagar

Thrissur-680555.

E-mail: drsathee171@gmail.com

DOI:10.14260/jemds/2015/2348.
This may increase the acceptance of regional anesthesia. Benzodiazepines, opioids are the commonly used sedatives. These drugs have the risk of respiratory depression, hemodynamic instability.

Clonidine and dexmedetomidine are $\alpha_{2}$-adrenoreceptor agonists with anxiolytic and dose-related sedative properties. In addition to above properties, they provide good analgesia devoid of respiratory depression.

Alpha-2 agonists such as clonidine, dexmedetomidine used in this study can be a useful adjuvant to local anesthetics. ${ }^{2,3}$

Perioperative pain management is important in such a way that they are intended to reduce or eliminate postoperative pain. Hence clonidine and dexmedetomidine an alpha- 2 agonists used in this study with the aim of producing perioperative analgesia and patient comfort, therefore reduces the requirement of other intravenous analgesics.

\section{OBJECTIVES}

1. To compare the clinical effects of epidural dexmedetomidine and clonidine with epidural ropivacaine in patients undergoing Elective Abdominal Hysterectomy.

2. To find out the time of first epidural top up.

3. To find the number of analgesic requirement until the time of first epidural top up.

\section{MATERIALS AND METHODS}

This study was conducted after obtaining approval of Institutional Technical Committee and Human Ethical Committee of Government Medical College, Thrissur. 


\section{STUDY SUBJECTS}

American society of anesthesiologists PS I and II patients of female sex, aged 30-60 years, who had undergone elective Abdominal Hysterectomy in Govt. Medical College Hospital, Thrissur were enrolled for study.

\section{Inclusion Criteria}

Patients undergoing elective Abdominal Hysterectomy. American society of Anesthesiologist (ASA) I and II.

Age between 30-60yrs.

Weight between $40-80 \mathrm{~kg}$.

Height between $145-165 \mathrm{~cm}$.

\section{Exclusion Criteria}

Patient refusal.

Patients on sympathomimetics, sympatholytic or Anticholinergic drugs.

Known hypersensitivity to, Dexmedetomidine/Clonidine/ Local anesthetics.

Sample Size 120 patients were allocated into 3 groups- each group containing 40 patients. A, B and C.

\section{METHODOLOGY}

All patients were examined the day before surgery. Procedure was explained to them in detail. A written informed consent in the local language was obtained from the patient and relative. Fasting for 8 hours before surgery was advised. Tab. Ranitidine $150 \mathrm{mg}$ and Metoclopramide $10 \mathrm{mg}$ was given on the night and at 6 am on the day before surgery.

- Patients were secured with good intravenous access and preloaded with $500 \mathrm{ml}$ normal saline $15 \mathrm{~min}$ before surgery.

- Monitors-pulse oximetry, ECG, NIBP.

- Under asepsis, lumbar epidural block was administered by a qualified anesthesiologist with patient in lateral decubitus position at L3-L4 space with 18G tuohy needle and catheter was secured $4 \mathrm{cms}$ into epidural space and test dose of $3 \mathrm{ml}$ of $2 \%$ lignocaine hydrochloride solution containing adrenaline (1:2,00,000 dilution) injected. After 3 minutes following negative aspiration for blood.

- Group R: Received $17 \mathrm{ml}$ of $0.75 \%$ ropivacaine.

- Group RC: Received $16 \mathrm{ml}$ of $0.75 \%$ ropivacaine $+2 \mathrm{mcg}$ per $\mathrm{kg}$ clonidine (Diluted to $1 \mathrm{ml}$ with normal saline).

- Group RD: Received $16 \mathrm{ml}$ of $0.75 \%$ ropivacaine $+1.5 \mathrm{mcg}$ perKg dexmedetomedine (Diluted to $1 \mathrm{ml}$ with normal saline).

- The following variables were measured during the study.

1. Evolution of sensory block was performed by pin-prick method with $22 \mathrm{G}$ needle in midclavicular line at 5,10 , 15, 20 minutes were noted. Time of onset of sensory block level at T6, peak sensory block level was also noted.

2. The quality of block evaluated according to the need for supplementary analgesia.

a) Adequate epidural- no supplementary analgesia required.

b) Inadequate epidural- Supplementation of $5 \mathrm{ml}$ of $0.75 \%$ ropivacaine required to complete surgery.

c) Failed epidural- General Anaesthesia required to complete surgery.
3. Evolution and grading of motor block assessed using Bromage scale at 5, 10, 15 and $20 \mathrm{~min}$ till the time of skin incision.

a) Full flexion of knees and feet.

b) Just able to flex knees, full flexion of feet.

c) Unable to flex knees, but some flexion of feet possible.

d) Unable to move legs or feet.

Heart rate (HR), Systolic blood pressure (SBP), Diastolic blood pressure (DBP), 02 saturation (SPO2) were monitored continuously and recordings made every 2 mins for $20 \mathrm{~min}$ till the surgery is started and at 5 min interval till the surgery is completed. Fluids were administered intraoperatively on the basis of changes in blood pressure and estimated blood loss.

Injection Mephentermine was given in $3-6 \mathrm{mg}$ increments intravenously if systolic BP decreased $>20 \%$ from baseline value despite adequate crystalloid infusion. Injection atropine $0.3-0.6 \mathrm{mg} \mathrm{I} / \mathrm{V}$ was given if heart rate decreased to $<50 /$ minute.

After surgery, time taken for two segment regression, regression to $\mathrm{S} 1$ dermatome was assessed by pinprick test every 15 minutes.

After surgery, the degree of motor blockade was assessed every 15 minutes till Bromage score of 1.

Duration of analgesia or the time of first epidural top up is the time interval between the administration of epidural injection and the first analgesic requirement for a pain score of $>3$ on numerical rating scale at the operated site.

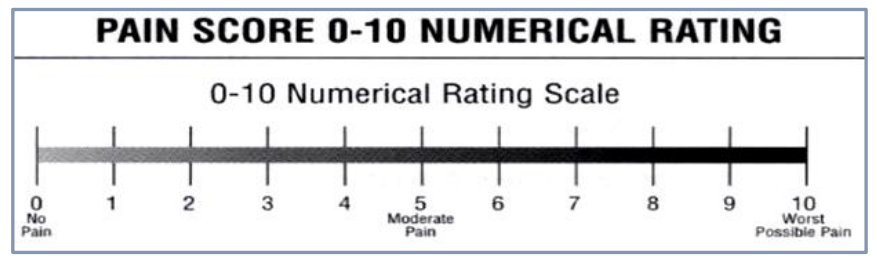

Table 1: Numerical Rating Scale

The onset of pain was managed by top up doses of $8 \mathrm{ml}$ of $0.2 \%$ ropivacaine (As a rescue analgesic) in the postoperative period. Sedation score was noted using Ramsay sedation scale every $15 \mathrm{~min}$. until the patient complains of pain.

\section{Ramsay sedation scale is as follows}

1. Patient is anxious and agitated or restless or both.

2. Patient is cooperative, oriented and tranquil.

3. Patient responds to commands only.

4. Patient has a brisk response to a light glabellar tap or loud auditory stimulus.

5. Patient asleep, sluggish response to light glabellar tap or loud auditory stimulus.

6. Patient does not respond to painful stimulus.

\section{OBSERVATIONS AND RESULTS}

The observations made were tabulated and analyzed using computer software, Statistical Package for Social Sciences. Mean, Standard error, Oneway Anova and Bonferroni were used to compare quantitative variables. Qualitative variables were compared using Chi-Square Tests.

The patients in three groups were comparable with respect to age, sex, weight and ASA PS. Two patients from group $\mathrm{R}$, 4 patients from group $\mathrm{RD}$ and 1 patient from group $\mathrm{RC}$ were converted to GA. 


\begin{tabular}{|c|c|c|c|c|}
\hline PARAMETERS & GROUP R & GROUP RD & GROUP RC & $\begin{array}{c}\text { P } \\
\text { VALUE }\end{array}$ \\
\hline WEIGHT(KG) & $55.40 \pm 5.163$ & $51.82 \pm 5.231$ & $55.00 \pm 4.324$ & .003 \\
\hline \multicolumn{6}{|c|}{ Table 2: Comparison of Weight among groups } \\
\hline
\end{tabular}

The mean weight of groups R, RD and RC were 55.40, 51.82 and 55.00 respectively. The difference in mean weight among groups was statistically significant with P value.003.

\begin{tabular}{|c|c|c|c|}
\hline GROUPS & MEAN & SD & \multirow{2}{*}{ P VALUE } \\
\hline GROUP R & 42.85 & 4.897 & \\
\cline { 1 - 3 } RD & 44.44 & 4.453 & \multirow{2}{*}{0.242} \\
\hline RC & 44.13 & 8.203 & \\
\cline { 1 - 2 } Table 3: Comparison of age (Years) between groups \\
\hline
\end{tabular}

The mean age was comparable between groups. There was no significant difference between groups with $p$ value of 0.242

\begin{tabular}{|c|c|c|c|}
\hline GROUP S & MEAN & SD & P VALUE \\
\hline GROUP R & 1.18 & 0.385 & \\
\cline { 1 - 2 } GROUP RD & 1.26 & 0.442 & \multirow{2}{*}{0.657} \\
\cline { 1 - 2 } GROUP RC & 1.20 & 0.401 & \\
\hline \multicolumn{3}{|c|}{ Table 4: Comparison of ASA between groups } \\
\hline
\end{tabular}

The mean ASA was comparable between groups $\mathrm{R}, \mathrm{RD}$ and RC. The difference among groups was not statistically significant.

\begin{tabular}{|c|c|c|c|}
\hline GROUPS & MEAN & SD & P VALUE \\
\hline GROUP R & 95.88 & 13.723 & \multirow{2}{*}{0.158} \\
\hline GROUP RD & 99.36 & 10.710 & 10.097 \\
\hline GROUP RC & 100.73 & Table 5: Comparison of Mean Duration of \\
Surgery between groups \\
\hline \multicolumn{4}{|c|}{} \\
\hline
\end{tabular}

The mean duration of surgery was comparable between groups R, RD and RC. The difference among groups was not statistically significant.

\section{COMPARISON OF HEART RATE}

Heart rate was comparable between groups. There was statistically significant difference noted at time intervals 0,2,4,6,8,10,12,14,16,18,20,25,30,35,40,45,50,55,60,65,70,75, $80,85,90,95,100$ min (With $P$ value $<0.05$ ) when compared between groups R and RC.

There was statistically significant difference noted at time intervals $6,8,10,12,14,16,18,20,25,30,35,40,45,50,55$, $60,65,70,75,80,85,90,95,100,105$ min (with $P$ value<0.05) when compared between groups R and RD.

There was no significant difference between groups RD and RC.

There was fall in heart rate in all groups.

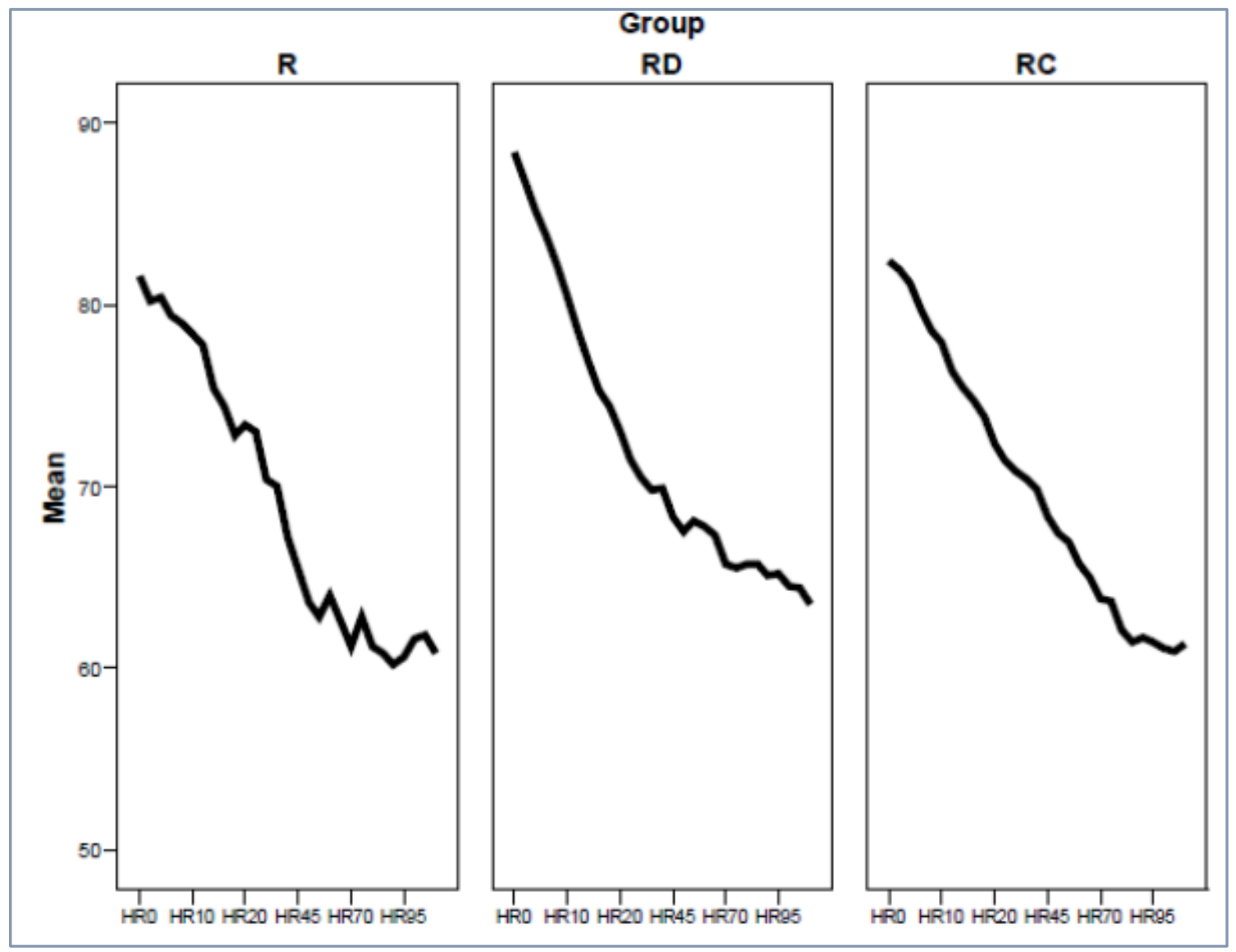

Comparison of Heart Rate during Surgery

\section{Comparison of Systolic Blood Pressure}

There was significant difference with p value $<0.05$ noted at time intervals 35 min., $60 \mathrm{~min}$. between groups R and RC, 80 min. between groups $\mathrm{R}$ and RD, $85 \mathrm{~min}$. between groups $\mathrm{R}$ and $\mathrm{RD}$ and $\mathrm{R}$ and RC.

There was fall in Systolic blood pressure in groups RD and RC than group R. 


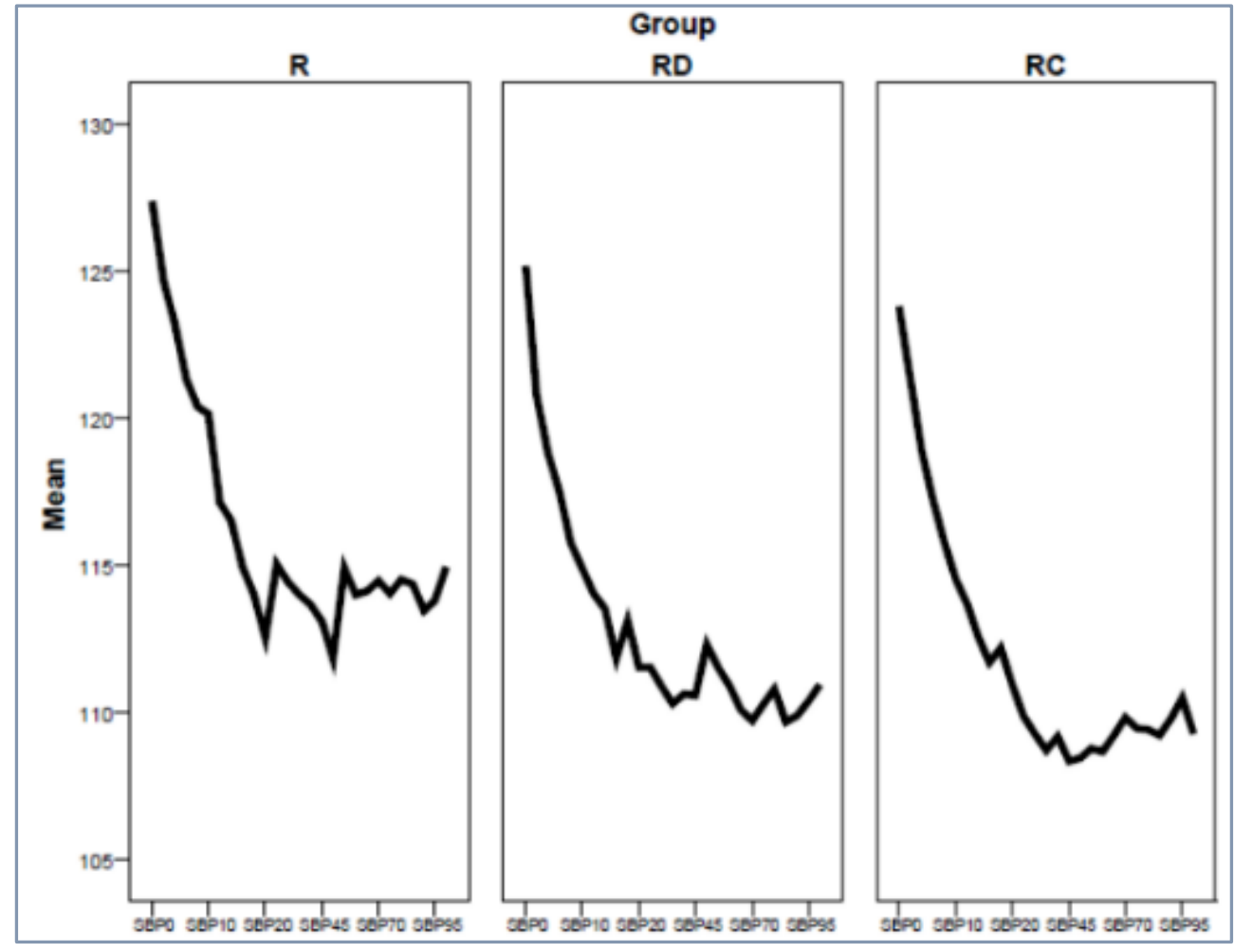

Comparison of Systolic Blood Pressure during Surgery

\section{Comparison of Diastolic Blood Pressure}

There was significant difference with p value $<0.05$ noted at $20,25,30,35,40,45,50,55,60,65,70,75,80,85,90,95,100$ and 105 min between groups R and RD and group R and RC respectively.

There was a fall in diastolic blood pressure in both groups RD and RC than group R.

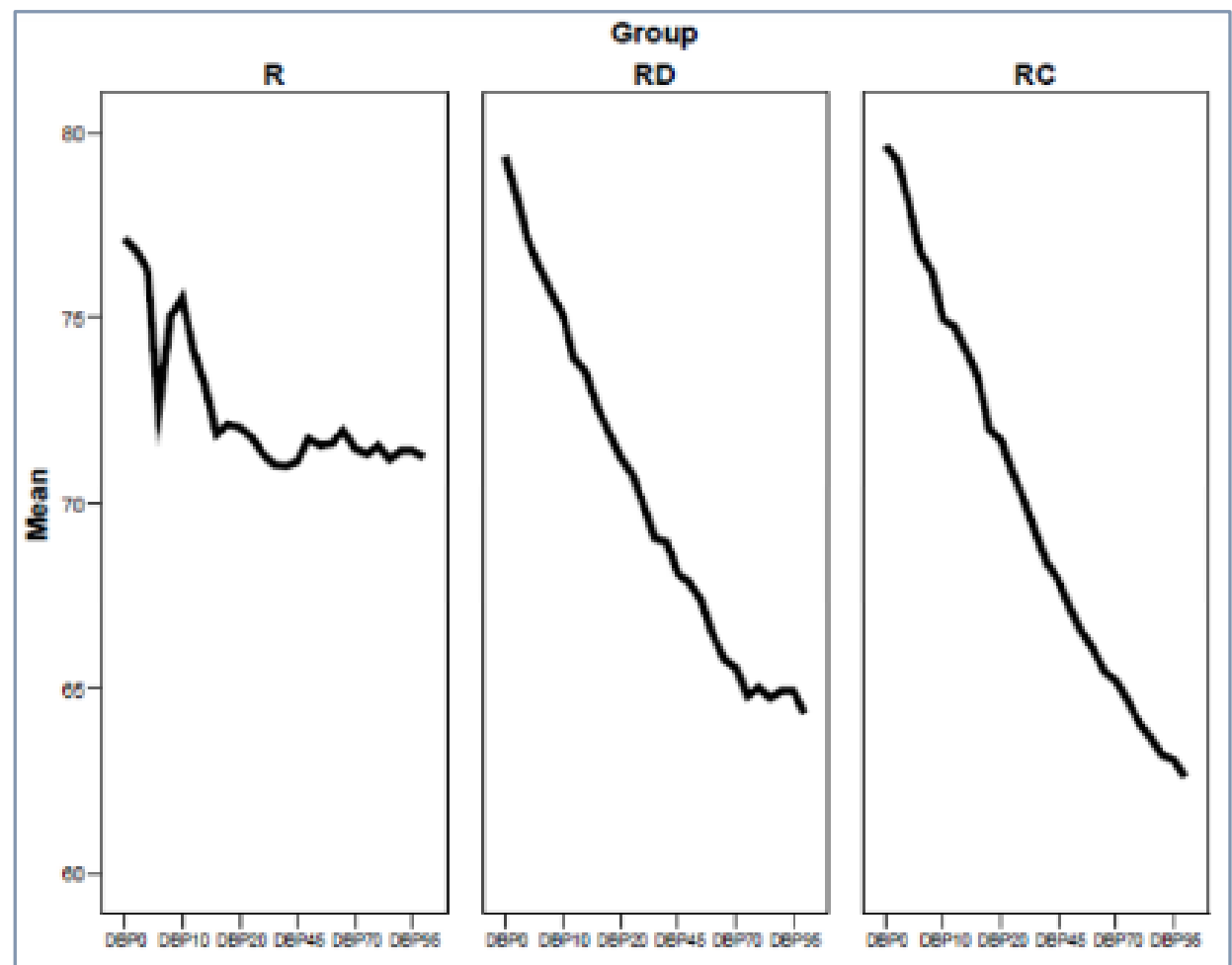

Comparison of Diastolic Blood Pressure during Surgery 


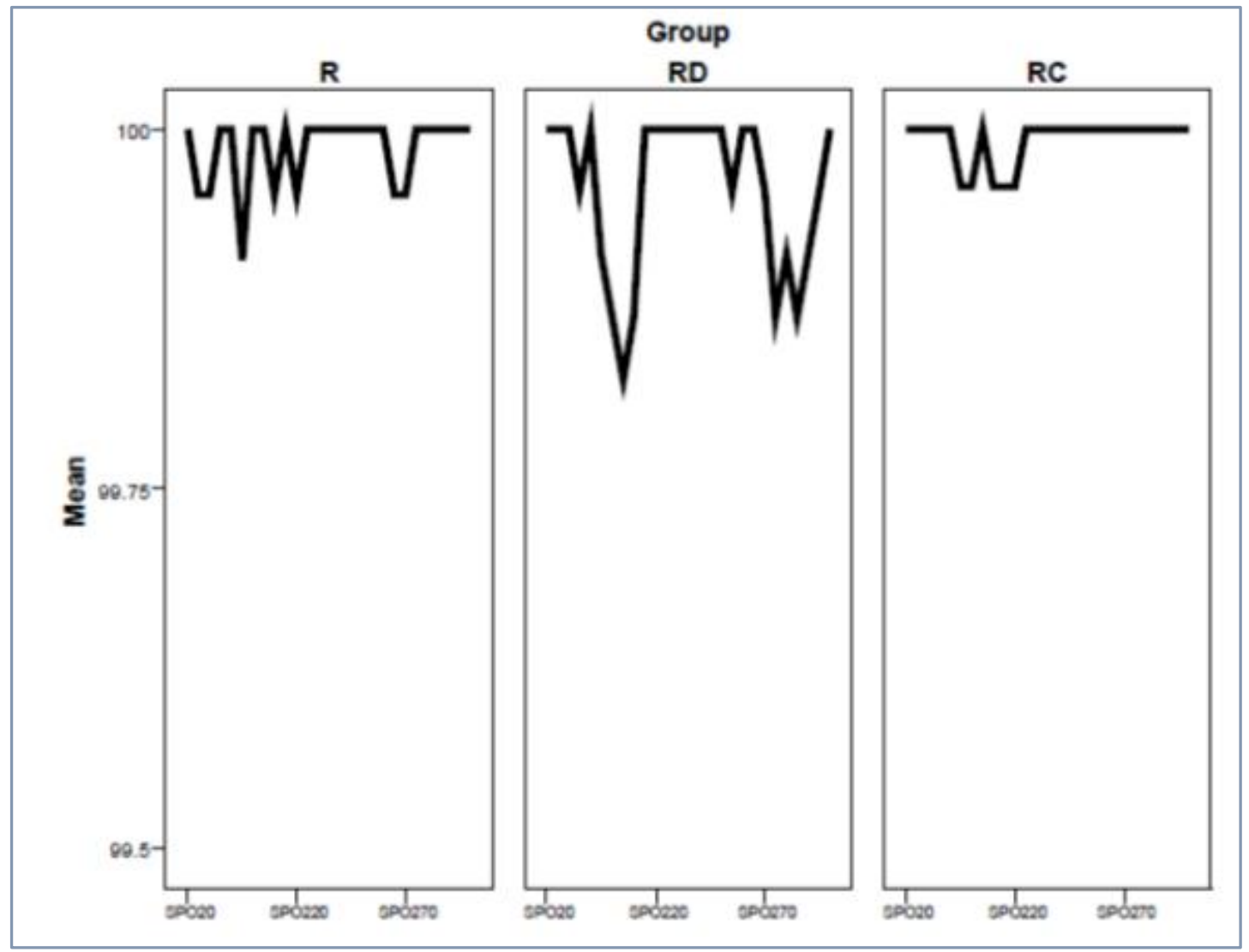

Comparison of SPO2 between Groups

There was a slight fall in SPO2 in group RD than group R and RC.

\begin{tabular}{|c|c|c|c|}
\hline Variable & Group R & Group RD & Group RC \\
\hline $\begin{array}{c}\text { T6 } \\
\text { (minutes) }\end{array}$ & $13.95 \pm 3.110$ & $14.03 \pm 2.624$ & $15.90 \pm 1.994$ \\
\hline \multicolumn{3}{|c|}{ Table 6: Meantime of Onset of Sensory Block at T6 } \\
\hline
\end{tabular}

*time of onset of sensory block at T6 dermatome

\begin{tabular}{|c|c|}
\hline Groups Compared & P value \\
\hline R \& RD & .894 \\
\hline R \& RC & .001 \\
\hline RD \& RC & .002 \\
\hline \multicolumn{2}{|c|}{ Table 7: Comparison of Time of Onset of } \\
Sensory Block at T6 between Groups \\
\hline
\end{tabular}

Onset of sensory block at $\mathrm{T} 6$ is the time interval between the administration of epidural block and sensory block at T6 dermatome.

It was comparable between groups.

It was 13.95 minutes in group $\mathrm{R}, 14.03$ minutes in group $\mathrm{RD}$ and 15.90 minutes in group RC.

There was no significant difference when compared between group R and RD.

The time to reach sensory level T6 was attained earlier in group R.

There was significant difference with $P$ value $<0.05$ when compared between groups R and RC, groups RD and RC.

\begin{tabular}{|c|c|c|c|}
\hline GROUP & T6 & T5 & T4 \\
\hline R & 17 & 0 & 20 \\
\hline RD & 11 & 0 & 26 \\
\hline RC & 17 & 0 & 22 \\
\hline \multicolumn{4}{|c|}{ Table 8: Comparison of Peak Sensory } \\
Level Between Groups
\end{tabular}

The peak sensory level was comparable between groups.

\begin{tabular}{|c|c|c|c|}
\hline Variable & Group R & $\begin{array}{c}\text { Group } \\
\text { RD }\end{array}$ & Group RC \\
\hline $\begin{array}{c}\text { Time to maximum } \\
\text { motor blockade }\end{array}$ & $3.00 \pm .000$ & $3.00 \pm .000$ & $3.00 \pm .000$ \\
\hline \multicolumn{3}{|c|}{ Table 9: Maximum, Motor Blockade between Groups } \\
\hline
\end{tabular}

All the 113 patients achieved Bromage scale 3.

There was no significant difference between groups.

\begin{tabular}{|c|c|c|c|}
\hline Variable & Group R & Group RD & Group RC \\
\hline $\begin{array}{c}\text { Time of } \\
\text { first } \\
\text { epidural } \\
\text { top up }\end{array}$ & $222.37 \pm 41.942$ & $497.78 \pm 61.788$ & $314.74 \pm 34.469$ \\
\hline \multicolumn{3}{|c|}{ Table 10: Comparison of Mean Time } \\
of First Epidural Top-up \\
\hline
\end{tabular}

The mean time of first epidural top up was $222 \mathrm{~min}$. in R, 497 in RD and 314 min. in gp RC.

There was statistically significant difference between groups with P value of.000. It was significantly prolonged in group RD than group RC and R.

\begin{tabular}{|c|c|c|c|}
\hline Variable & Group R & $\begin{array}{c}\text { Group } \\
\text { RD }\end{array}$ & Group RC \\
\hline Sedation score & $1.97 \pm .162$ & $\begin{array}{c}2.19 \pm .40 \\
1\end{array}$ & $2.00 \pm .397$ \\
\hline \multicolumn{2}{|c|}{ Table 11: Comparison of Mean Sedation Score } \\
\hline
\end{tabular}

\begin{tabular}{|c|c|}
\hline Groups Compared & P value \\
\hline R \& RD & .006 \\
\hline R \& RC & .734 \\
\hline RD \& RC & .014 \\
\hline Table 12: Mean Sedation Score between Groups \\
\hline
\end{tabular}


Sedation score was comparable between groups. Sedation score was better in group $\mathrm{RD}$ than group $\mathrm{RC}$ and group R.

There was statistically significant difference when compared between groups $\mathrm{R}$ and $\mathrm{RD}$, groups $\mathrm{RD}$ and $\mathrm{RC}$.

\begin{abstract}
Adverse Effects
Dryness of mouth was noted in 4 patients from group RD and 7 patients from group RC. There was no incidence of nausea, vomiting and shivering. Hypotension was noted in 12 patients from group R, 11 patients from group RD and 11 patients from group RC and treated with $6 \mathrm{mg}$ of mephentermine.

Bradycardia was noted in 2 patients from group $\mathrm{R}$ and $\mathrm{RD}$, one patient from group RC. It was treated with $0.6 \mathrm{mg}$ atropine. There was no analgesic requirement till first epidural top up.
\end{abstract}

\section{DISCUSSION}

\section{Ropivacaine}

Ropivacaine is a long-acting amide local anesthetic and is first produced as a pure enantiomer. It was first synthesized by Ekenstam in 1957. Available as sterile nonpyrogenic aqueous solution of ropivacaine hydrochloride with $\mathrm{p}^{\mathrm{H}} 8.1$, in $10 \mathrm{ml}$ or $20 \mathrm{ml}$ ampoules. The concentrations available are $7.5 \mathrm{mg} / \mathrm{ml}$, $5 \mathrm{mg} / \mathrm{ml}, 2 \mathrm{mg} / \mathrm{ml}$.

\section{Mechanism of Action}

Ropivacaine causes reversible blockade of voltage dependent $\mathrm{Na}^{+}$channels as similar to other.

\section{Cardiovascular and Central Nervous System Effects and Toxicity}

The potency for toxicity reflects the anesthetic potency of the agent. ${ }^{4}$ Ropivacaine possess a greater margin of safety than bupivacaine if one compares the dose to cause convulsions and cardiovascular collapse, death. Lignocaine is the only agent devoid of arrhythmogenic potential.5,6,7

Potency for CNS Toxicity- Bupivacaine- 4, Ropivacaine - 2.9.8 Effects on uterine blood flow and placental transfer-Neither ropivacaine nor bupivacaine administered in the pregnant ewes had led to any ill effects on the uterine artery blood flow or fetal well-being. ${ }^{9} \mathrm{~F} / \mathrm{M}$ ratio of ropivacaine is 0.2 .

\section{CLINICAL APPLICATIONS}

\section{Epidural Administration}

Various studies of lumbar epidural administration of $0.5 \%$, $0.75 \%$ and $1 \%$ concentration of ropivacaine showed that it provides surgical anesthesia of good quality and longer duration. 10,11 Increasing the concentration of drug decreases the onset time and increased motor block as seen with other local anesthetics. ${ }^{12}$ The peak plasma concentration of ropivacaine was below the concentration associated with systemic toxicity in animals.

\section{Intrathecal Administration}

In a safety study, spinal administration of $3 \mathrm{ml}$ of $0.5 \%$ or $0.75 \%$ ropivacaine (Glucose free) was compared. The incidence of complete motor blockade and prolonged duration of analgesia was higher with $0.75 \%$ ropivacaine. ${ }^{13}$ The coadministration of opioids reduces the total dose of local anesthetic required for anesthesia and significantly prolongs the duration of complete and effective analgesia. ${ }^{14}$

\section{Peripheral Nerve Blocks}

Hickey and Colleagues found that $0.5 \%$ ropivacaine was comparable with $0.5 \%$ bupivacaine in terms of onset time, duration of effect and motor block. $(14,15)$

\section{Labour Analgesia}

In a study conducted, compared $0.25 \%$ ropivacaine with $0.25 \%$ bupivacaine $6-12 \mathrm{ml} / \mathrm{hr}$. after a bolus dose of $10 \mathrm{ml}$ of same concentration, there was effective pain relief in labour and no difference in the mode of delivery and neonatal outcome.(16)

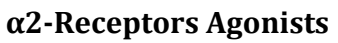

They include centrally-acting $\alpha_{2}$-adrenergic receptor agonists, clonidine and dexmedetomidine, which have potent sedative and opioid analgesic-sparing properties. They can reduce the intravenous and volatile anesthetic requirements as well as the postoperative opioid requirement. They provide effective analgesia for acute and chronic pain, particularly as adjuncts to local anesthetics and opioids.

\section{Clonidine}

Clonidine is a prototype of $\alpha 2$ agonist. It is a centrally acting selective partial $\alpha_{2}$ adrenergic agonist (220:1 $\alpha_{2}$ to $\alpha_{1}$ ). It can be added to local anesthetics for epidural, spinal, or regional blocks, and therefore intensifies the anesthesia. Traditionally, it has been used as antihypertensive drug. Further applications based on their sedative, anxiolytic, and analgesic properties are being developed.

\section{Mechanism of Action}

In addition to above actions of alpha- 2 agonists, Clonidine also stimulates $\alpha_{2}$ receptors in the vasomotor centers of the medulla oblongata. It is thought to produce decrease in sympathetic nervous system outflow from central nervous system to peripheral tissues, which is manifested as peripheral vasodilatation and decrease in systemic blood pressure, heart rate and cardiac output. ${ }^{17}$

Neuraxial administration of clonidine directly inhibits sympathetic preganglionic neurons in the spinal cord 60 producing analgesia by inhibition of substance $P$.

\section{Dexmedetomidine}

Dexmedetomidine is a D enantiomer of medetomidine. It is a more selective $\alpha_{2}$ agonist than clonidine (1,620:1 $\alpha_{2}$ to $\alpha_{1}$ ). It was introduced into clinical practice as an adjunct to regional, local, and general anesthetics. It provides excellent sedation, reduces blood pressure, HR and profoundly decreases plasma catecholamines. It reduces the requirements for volatile anesthetics, sedatives and analgesics without causing significant respiratory depression.

It has been presently approved by the Food and Drug Administration only for brief $(<24$ hours $)$ postoperative sedation, although it is finding increasing use in the perioperative period as an adjunct sedative. Its clinical advantage is that it produces a unique type of sedationanalgesia with less ventilatory depression.(18) than the commonly used sedative-hypnotic and opioids analgesic drugs.

Available as $0.5 \mathrm{ml}, 1 \mathrm{ml}, 2 \mathrm{ml}$ ampoules containing 100 $\mathrm{mcg} / \mathrm{ml}$ diluted in $0.9 \%$ saline. 


\section{Mechanism of Action}

Its primary action is agonist at alpha-2 receptors in the locus coeruleus inhibits the release of nor epinephrine and results in sedation, hypnosis. Stimulation of $\alpha 2$-receptors at the substantia gelatinosa of the dorsal horn of the spinal cord leads to inhibition of the release of substance $P$ resulting in analgesia.

Neuraxial opioids are standard analgesics for postoperative pain management. The use of alpha- 2 agonist such as clonidine has several advantages over epidurally administered opioids as it is devoid of side effects such as pruritus, nausea, vomiting, respiratory depression and urinary retention. In addition, clonidine have synergistic action when used as adjuvant to local anesthetic resulting in postoperative analgesic requirement. $(19,20)$

The use of dexmedetomidine, an alpha-2 agonist got FDA approval only for sedation in intensive care.

Various studies have shown that use of dexmedetomidine reduces peri-operative analgesic requirements.(21,22) and provides opioids sparing effect with minimal adverse effects.

The stable hemodynamic with sedation and prolonged postoperative analgesia makes these alpha- 2 agonists an effective adjuvant in regional anesthesia.

This study was conducted to analyse the effects of epidural dexmedetomidine and epidural clonidine when used as an adjuvant to epidural ropivacaine for abdominal hysterectomy.

A prospective cohort study was conducted in 120 female patients of ASA PS I and II who met inclusion criteria and had undergone abdominal hysterectomy in Government Medical College, Thrissur.

- Sukhminder Jit Singh Bajwa et al. compared the efficacy and clinical profile of two alpha-2 agonists, dexmedetomidine and clonidine in combination with ropivacaine in epidural anesthesia for vaginal hysterectomies. The patients were randomly allocated into two groups to receive group $\mathrm{RD}$ with ropivacaine $17 \mathrm{ml}$ $0.75 \%+$ dexmedetomidine $1.5 \mathrm{mcg} / \mathrm{kg}$ and group RC with ropivacaine $17 \mathrm{ml} 0.75 \%+$ clonidine $2 \mathrm{mcg} / \mathrm{kg}$. The parameters such as onset of analgesia, sensory and motor block levels duration of analgesia, sedation, and side effects were observed. Both groups were comparable and observed that dexmedetomidine is a better neuraxial adjuvant compared to clonidine for providing early onset of sensory analgesia, adequate sedation and a prolonged postoperative analgesia.(23)

- Sample size was calculated as 40 in each group using the formula $(\mathrm{Z} \alpha+\mathrm{Z} \beta)^{2} \times \mathrm{pq} \times 2 / \mathrm{d} 2$.

- Patients were selected into one of the three groups by lot method.

- Group R : Received $17 \mathrm{ml}$ of $0.75 \%$ ropivacaine.

- Group RC: Received $16 \mathrm{ml}$ of $0.75 \%$ ropivacaine $+2 \mathrm{mcg}$ per $\mathrm{kg}$ clonidine. (Diluted to $1 \mathrm{ml}$ with normal saline).

- Group RD: Received $16 \mathrm{ml}$ of $0.75 \%$ ropivacaine $+1.5 \mathrm{mcg}$ per $\mathrm{kg}$ dexmedetomidine (Diluted to $1 \mathrm{ml}$ with normal saline).

The clinical parameters such as heart rate, systolic blood pressure, diastolic blood pressure were compared. There was fall in systolic blood pressure and diastolic blood pressure in both groups RD and RC. There was fall in heart rate in all groups.
The values of heart rate, systolic blood pressure and diastolic pressure were comparable till $95 \mathrm{~min}$. as there were few values beyond.

The onset of sensory block at T6 was compared between groups. Evolution of sensory block was assessed by pin prick method with $24 \mathrm{G}$ needle at 5, 10, 15 and 20 minutes till the time of skin incision.

The mean time of onset of sensory block at T6 was 13.95 min. in group R, $14.03 \mathrm{~min}$. in group RD and $15.90 \mathrm{~min}$. in group RC. There was no significant difference when compared between group $\mathrm{R}$ and RD.

There was significant difference with $P$ value $<0.05$ when compared between groups R and RC, groups RD and RC.

The next parameter compared was maximum sensory level achieved. The maximum sensory level attained is T4. The peak sensory level was comparable between groups. It was $2.11 \pm 1.008$ in group $\mathrm{R}, 2.39 \pm .934$ in group $\mathrm{RD}, 2.13 \pm 1.005$ in group RC. There was no significant difference between the groups.

The maximum motor blockade was compared between groups. It was comparable between groups. There was no significant difference between groups. The evolution of motor blockade was done by Bromage scale.

All the 113 patients attained Bromage scale 3.

Post-operative block characteristics such as the time of regression to Bromage scale 1 were compared. The time of regression to Bromage scale 1 was comparable between groups with $201.05 \mathrm{~min}$. in group R, $310.28 \mathrm{~min}$. in group RD and $265.90 \mathrm{~min}$. in group RC. There was significant difference found between all the groups with $\mathrm{P}$ value $<0.05$.

The time of two segment regression was compared between groups. It was comparable and significant difference was found between groups with $P$ value $<0.05$. The time taken for two segment regression was $187.89 \mathrm{~min}$. in group R, $278.61 \mathrm{~min}$. in group RD and $248.72 \mathrm{~min}$. in group RC.

The time of regression of sensory level to S1 dermatome was compared. It was comparable and significant difference found between groups with $P$ value $<0.05$. It was $223.68 \mathrm{~min}$. in group R, 495.83 min. in group RD and 313.97 min. in group RC. It was significantly prolonged in group RD.

The time of first epidural top up was compared between groups. It was statistically significant with $P$ value of $<0.05$. It was $222.37 \mathrm{~min}$. in group $\mathrm{R}, 497.78 \mathrm{~min}$. in group RD and 314.74 min. in group RC.

It was prolonged in group RD followed by group $\mathrm{RC}$ and group R.

Sedation score was compared between groups by Ramsay Sedation Scale. It was comparable, but no significant difference between groups.

Comparison of adverse effects such as nausea, vomiting, shivering, dryness of mouth was noted. There was no incidence of nausea, vomiting and shivering. Dryness of mouth was noted in 4 patients from group RD and 7 patients from group RC.

Incidence of mephentermine and atropine requirement was compared.

Twelve patients from group $\mathrm{R}, 11$ patients from group $\mathrm{RD}$ and 11 patients from group $\mathrm{RC}$ had hypotension and treated with $6 \mathrm{mg}$ of mephentermine.

Two patients from group R and RD, 1 patient from group $\mathrm{RC}$ had bradycardia and treated with $0.6 \mathrm{mg}$ atropine.

There was no analgesic requirement till first epidural top 


\section{CONCLUSION}

Epidural Dexmedetomidine and clonidine have synergistic action in combination with epidural ropivacaine resulting in smooth and prolonged postoperative analgesia and sedation.

Group RD had significant difference in comparison of postoperative block characteristics such as time of two segment regression, time to Bromage scale 1 , time of regression to S1 dermatome and time of first epidural top up than group RC and R.

Thus epidural dexmedetomidine is a better neuraxial adjuvant in combination with epidural ropivacaine in producing prolonged analgesia and better sedation for abdominal hysterectomy.

\section{REFERENCES}

1. Kenneth Drasner. Local Anesthetics. In: Ronald D. Miller, Manuel C. Pardo, ed. Basics of anesthesia, 6th ed. Philadelphia: Elsevier Saunders; 2011. p. 140.

2. Christopher M. Bernards. Epidural and Spinal Anesthesia. In: Paul G. Barash, Bruce F. Cullen, Robert K. Stoelting, Michael K. Cahalan, M. Christine Stock, ed. Clinical Anesthesia, 6th ed. Philadelphia: Lippincott Williams and Wilkins; 2009. p. 538-39.

3. Kamibayashi T, Maze M. Clinical uses of alpha-2 adrenergic agonists. Anaesthesiology 2000;93(5):1345-9.

4. Spencer S. Liu, Yi Lin. Local Anesthetics. In: Paul G. Barash, Bruce F. Cullen, Robert K. Stoelting, Michael K. Cahalan, M. Christine Stock, ed. Clinical Anesthesia, 6th ed. Philadelphia: Lippincott Williams and Wilkins; 2009. p. 542.

5. Feldman HS, Arthur GR, Covino BG. Comparative systemic toxicity of convulsant and supraconvalsant doses of intravenous ropivacaine, bupivacaine, and lidocaine in the conscious dog. Anesth Analg 1989;69:79.

6. Scott DB, Lee A, Fagan D, Bowler GMR, Bloomfield P, Lundh $\mathrm{R}$ : Acute toxicity of ropivacaine compared with that of bupivacaine. Anesth Analg 1989;69:563-9.

7. Reiz S, Nath S: Cardiotoxicity of local anaesthetic agents. $\mathrm{Br}$ J Anaesth 1986;58:736-46.

8. Spencer S. Liu, Yi Lin. Local Anesthetics. In: Paul G. Barash, Bruce F. Cullen, Robert K. Stoelting, Michael K. Cahalan, M. Christine Stock, ed. Clinical Anesthesia, 6th ed. Philadelphia: Lippincott Williams and Wilkins; 2009. p.541.

9. Santos AC, Arthur GR, Roberts DJ, Wlody D, Pedersen H, Morishima HO, Finster M, Covino BG: Effect of ropivacaine and bupivacaine on uterine blood flow in pregnant ewes. Anesth Analg 1992;74:62-67.

10. Concepcion M, Arthur GR, Steele SM, Bader AM, Covino BG. A new local anesthetic, ropivacaine. Its epidural effects in humans. Anesthesia and Analgesia 1990;70:80-85.

11. Whitehead E, Arrigoni B, Bannister J. An open study of ropivacaine in extradural anesthesia. British Journal of Anaesthesia 1990;64:67-71.
12. The United States of America: Churchil Livingstone, Elsevier; 2010. p.928-29 102. Scott DB, McClure JH, Giasi RM, SeoJ, Covino BG. Effects of concentration of local anesthetic drugs in extradural blockade. British 113010 Journal of Anaesthesia 1980;52:1033-1037.

13. Van Kleef JW, Veering BT, Burm AGL. Spinal anesthesia with ropivacaine. A double blind study on the efficacy and safety of $0.5 \%$ and $0.75 \%$ solutions in patients undergoing minor lower limb surgery Anesthesia and Analgesia 1994;78:1125-1130.

14. Hickey R, Blanchaed J, Hoffman J, Sjovall J, Ramamurthy S. Plasma concentrations of ropivacaine given with or without epinephrine for brachial plexus blockade. Canadian Journal of Anaesthesia 1990;37:878-882.

15. Hickey R, Hoffman J, Ramamurthy S. A comparison of ropivacaine $0.5 \%$ and bupivacaine $0.5 \%$ for brachial plexus block. Anesthesiology 1991;74:639-642.

16. Stientra R, Jonker TA, Bourdrez P, Kuijpers JC, Van Kleef JW, Lundberg U. Ropivacaine $0.25 \%$ versus bupivacaine $0.25 \%$ for continuous epidural analgesia in labor. A double blind comparison. Anesthesia and Analgesia 1995;80:285289.

17. Gaumann DM, Brunet PC, Jirounek P: Clonidine enhances the effects of lidocaine on C-fiber action potential. Anesth Analg 1992;74:719-25.

18. Paris A, Tonner PH (2005). "Dexmedetomidine in anaesthesia." Current Opinion in Anaesthesiology 18(4):412-8.

19. Foster JG, Rosenberg PH. Small dose of clonidine mixed with low-dose ropivacaine and fentanyl for epidural analgesia after total knee arthroplasty. $\mathrm{Br} \mathrm{J}$ Anesth 2004;93:670-7.

20. Sites BD, Beach M, Biggs R. Intrathecal clonidine added to a bupivacaine-morphine spinal anesthetic improves postoperative analgesia for total knee arthroplasty. Anesth Analg 2003;96:1083-8.

21. Gurbet A, Basaqan-Moqol E, Turker G. Intraoperative infusion of dexmedetomidine reduces perioperative analgesic requirements. Can J Anaesth 2006 July; 53(7):646-52.

22. Wahlander S, Frumento RJ, Wagener G. A prospective, double blind, randomized, placebo-controlled study of dexmedetomiodine as an adjunct to epidural analgesia after thoracic surgery. J Cardiothoracic Vasc Anesth 2005 Oct;19(5):630-5.

23. Sukhminder Jit Singh Bajwa, Sukhwinder Kaur Bajwa, Jasbir Kaur, Gurpreet Singh, et al. Dexmedetomidine and clonidine in epidural anesthesia: A comparative evaluation. Indian Journal of Anesthesia 2011;55:116-2. 